\title{
Epidemiology of Intestinal Parasitism in Schoolchildren Treat- ed at the Primary Health System. Havana 2020
}

\author{
Osvaldo Batista Rojas, MSc* (D) \\ Eusebio Hernandez Gynecobstetric Hospital, Havana, Cuba
}

*Corresponding author: Osvaldo Batista Rojas, MSc, Assistant Professor and Researcher, Eusebio Hernandez Gynecobstetric Hospital, Havana, Cuba, Tel: +5356790289; +5372652681

\begin{abstract}
Introduction: Among infectious diseases, those caused by intestinal parasites constitute an important health problem for man.

Objective: To characterize the intestinal parasitism clinically and epidemiologically in primary school students from Marianao attended in the Primary Health Care, Havana, Cuba.

Methods: An observational, descriptive and cross-sectional study was carried out; the universe of study was represented by all schoolchildren from six Primary Schools in Marianao during the period from August 2018 to January 2020 with the clinical and microbiological diagnosis of intestinal parasitosis and they were treated at Five Family Medical Offices.

Results: There was a predominance of the female sex for $51.4 \%$. With greater predominance of the age group of 5 to 7 years for $33.8 \%$, abdominal pain was the most reported symptom by patients, found in 54 schoolchildren, followed by anal itching. Giardia lamblia in 52 schoolchildren for $29.7 \%$, followed by Enterobius vermicularis with $23.4,75 \%$ do not wash their hands, prior to eating food, $97 \%$ have Onychophagia.
\end{abstract}

Conclusions: Bad dietary hygiene habits are the main risk factors.

\section{Keywords}

Intestinal parasitism, Intestinal parasitosis, Parasites, Epidemiology, Schoolchildren

\section{Introduction}

Among infectious diseases, those caused by intestinal parasites constitute an important health problem for men, mainly in countries with less socioeconomic development. They have high prevalence rates and a wide distribution, and are detected more frequently in tropical and subtropical regions [1].

Intestinal parasitoses harm the economic development of nations and are closely linked with poverty and with the most underprivileged social sectors [2-4].

It is estimated that approximately 3 billion people worldwide are infected by intestinal parasites, both protozoa and helminths, and that about 1.45 billion correspond to helminths; the most prevalent species worldwide are: Ascaris lumbricoides, Trichuris trichiura, Ancylostoma duodenale and Necator americanus. Mortality from intestinal parasites is usually low, however between 3,000 and 65,000 deaths from soil-transmitted helminth infections and 100,000 from amebiasis are reported each year [5].

In Cuba there is government concern to improve the quality of life of the population, through the execution of multiple strategies and through the Ministry of Public Health, for which the country has managed to significantly improve the existing health indicators before 1959. A despite this, various investigations suggest the endemism of intestinal parasitism in rural and mountainous areas of the country $[6,7]$.

The current investigation is carried out with the objective of clinically and epidemiologically characterizing intestinal parasitism in schoolchildren from six Primary Schools of the Marianao Municipality in Havana.

\section{Material and Methods}

An observational, descriptive and cross-sectional study was carried out in the period from August 2018 to January 2020. The universe of the study is 1295 students

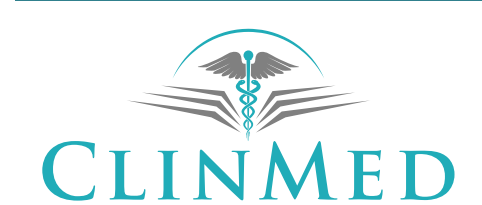

INTERNATIONAL LIBRARY
Citation: Rojas OB (2020) Epidemiology of Intestinal Parasitism in Schoolchildren Treated at the Primary Health System. Havana 2020. Int J Trop Dis 3:032. doi.org/10.23937/2643-461X/1710032

Accepted: June 02, 2020; Published: June 04, 2020

Copyright: (C) 2020 Rojas OB. This is an open-access article distributed under the terms of the Creative Commons Attribution License, which permits unrestricted use, distribution, and reproduction in any medium, provided the original author and source are credited. 
Table 1: Observations of parasitism according to age and gender.

\begin{tabular}{|c|c|c|c|c|c|c|}
\hline \multirow{3}{*}{ Group of age } & \multicolumn{4}{|c|}{ Sex } & & \\
\hline & \multicolumn{2}{|l|}{ Male } & \multicolumn{2}{|c|}{ Female } & \multicolumn{2}{|c|}{ Total } \\
\hline & No & $\%$ & No & $\%$ & No & $\%$ \\
\hline 5 to 7 & 87 & 34.0 & 91 & 33.6 & 178 & 33.8 \\
\hline 8 to 9 & 74 & 28.9 & 83 & 30.6 & 157 & 29.8 \\
\hline 10 to 11 & 54 & 21.1 & 67 & 24.7 & 121 & 23 \\
\hline 11 and more & 41 & 16.0 & 30 & 11.1 & 71 & 13.5 \\
\hline Total & 256 & 48.6 & 271 & 51.4 & 527 & 100 \\
\hline
\end{tabular}

Source: primary records

\section{Distribution by sex}

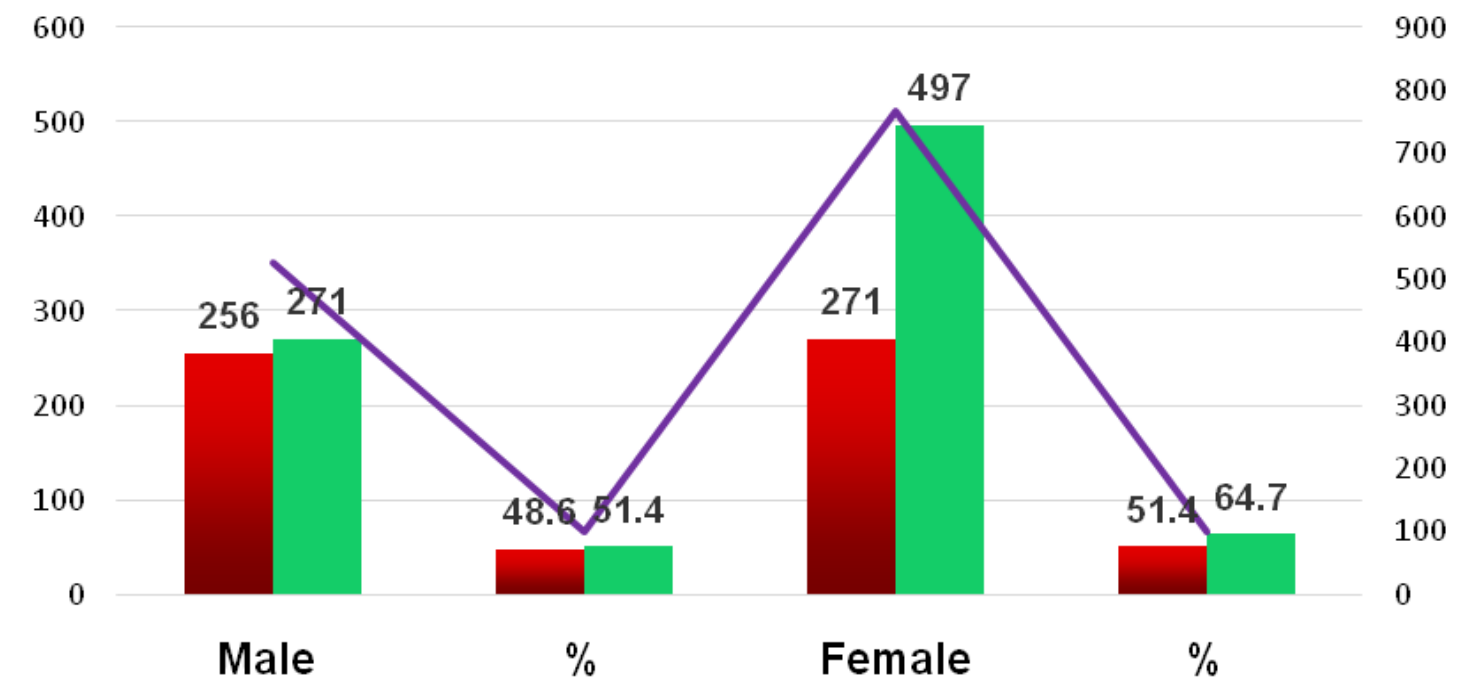

- Parasited No parasited - Total

Source: Individual clinical histories and parasitology studies.

Figure 1: Distribution of parasitism according to sex.

from the six selected primary schools, and the sample was all schoolchildren diagnosed with parasitism, that is, 527 belonging to ten Family Medical Offices.

Statistical information was obtained from the records on charge sheets and individual medical records of the patients studied and emptied by the author in a form designed for this purpose.

The variables studied were: Age in years, sex, municipality of origin, reported symptoms, type of parasite identified and risk factors.

The collected data was processed, creating a database through the statistical package SPSS for Windows version 11.5. Absolute frequencies and percentages were used as a summary measure of the information.

Ethical standards regarding the confidentiality of the information obtained were respected.

\section{Results}

In Table 1 a greater presence of sex observed female for $51.4 \%$ with greater predominance of the age group of 5 to 7 years for $33.8 \%$, followed by schoolchildren between 8 to 9 years with $29.8 \%$.

In Figure 1 you can see that the male sex was the most affected by parasitic infestations with $70.5 \%$, while

Table 2: Parasitic species found in schoolchildren.

\begin{tabular}{|l|l|l|}
\hline Found species & No. & Prevalence (\%) \\
\hline Trichuris trichiura & 27 & 14.4 \\
\hline Ascaris lumbricoides & 5 & 2.8 \\
\hline Strongyloides stercoralis & 3 & 1.7 \\
\hline Enterobius vermicularis & 41 & 23.4 \\
\hline Hymenolepis nana & 11 & 6.2 \\
\hline Entamoeba coli & 2 & 1.1 \\
\hline Endolimax nana & 6 & 3.4 \\
\hline Giardia lamblia & 52 & 29.7 \\
\hline Entamoeba histolytica & 25 & 14.2 \\
\hline
\end{tabular}

Source: Copro-parasitological study present in the Clinical Histories of the schoolchildren. 
females had a high index but with $62.8 \%$.

In Figure 2 it is evident that abdominal pain was the symptom reported by the patients, found on 54 schoolchildrens, followed by anal prurito with 37 and flatulence with 31 schoolchildren is valid to clarify that same patient were more of one of these symptoms.

In Table 2 and Figure 3 is found that the parasite more isolated in stool samples corresponded to the Giardia lamblia in 52 school for $29.7 \%$, followed by the Enterobius vermicularis with $23.4 \%$ and thirdly Entamoeba histolítyca with one $14.2 \%$, followed by Trichuris trichiura with $14.4 \%$. In addition to the presence or absence of monoparasitism and polyparasitism, where polyparasitism predominates in both sexes.

In Figure 4 shows that of the students studied, 75\% do not wash their hands, prior to eating food, $67 \%$ have Onychophagia followed by inadequate storage of drinking water with $59 \%$ having onychophagia or sucking the fingers.

\section{Discussion}

In a study carried out by Escobedo on prevalence and

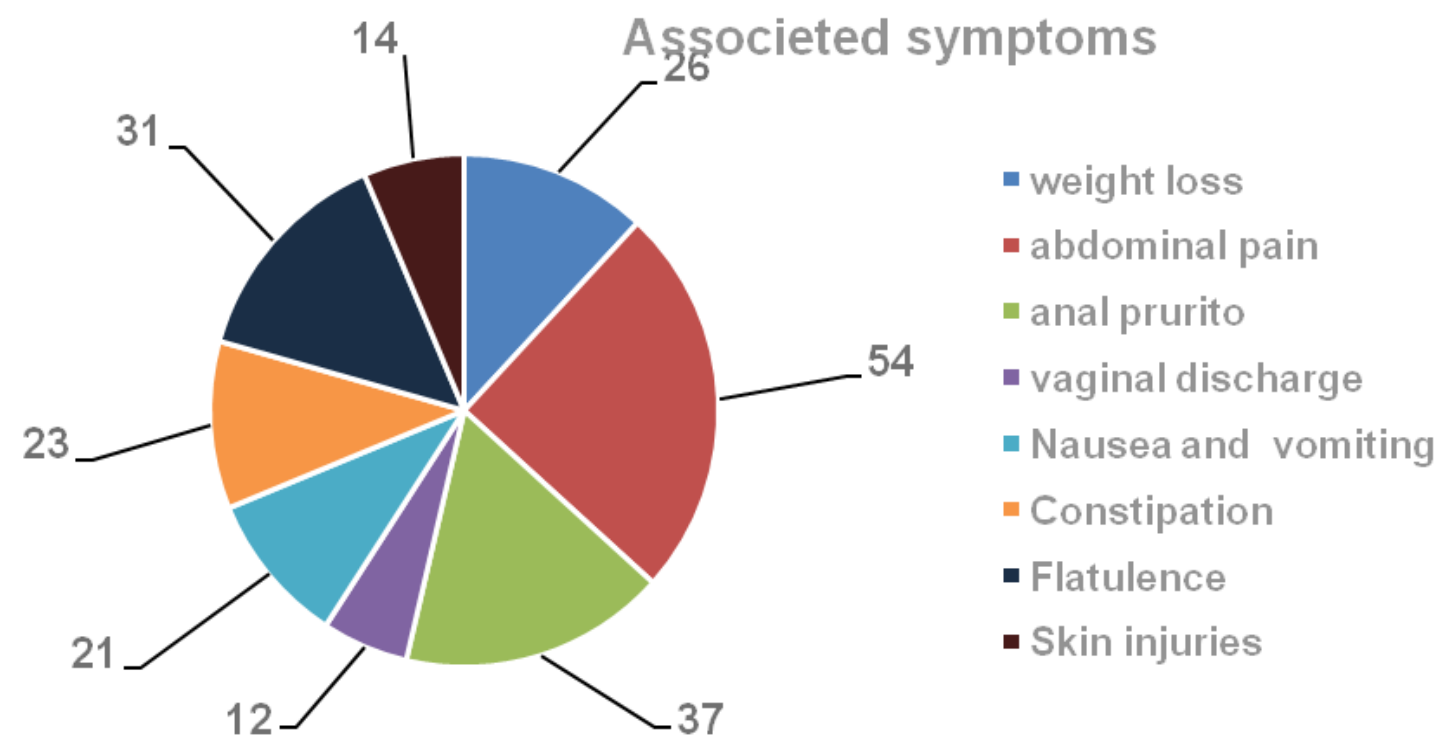

Source: Individual Clinical Histories.

Figure 2: Symptoms reported by the patients.

\section{Global presence of parasitims}

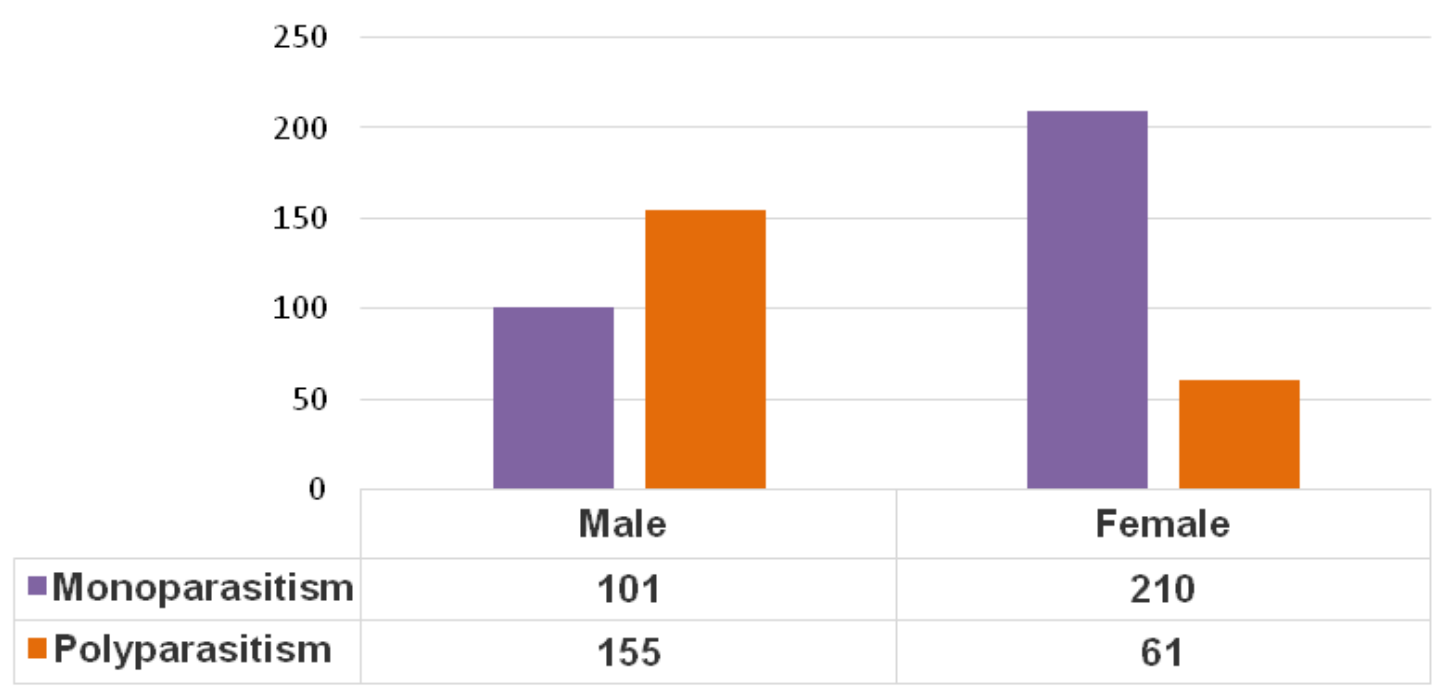

\section{- Monoparasitism - Polyparasitism}

Source: Copro-parasitological study

Figure 3: Global presence of parasitism according to incidence. 


\section{Epidemiological riks and parasite incidence}

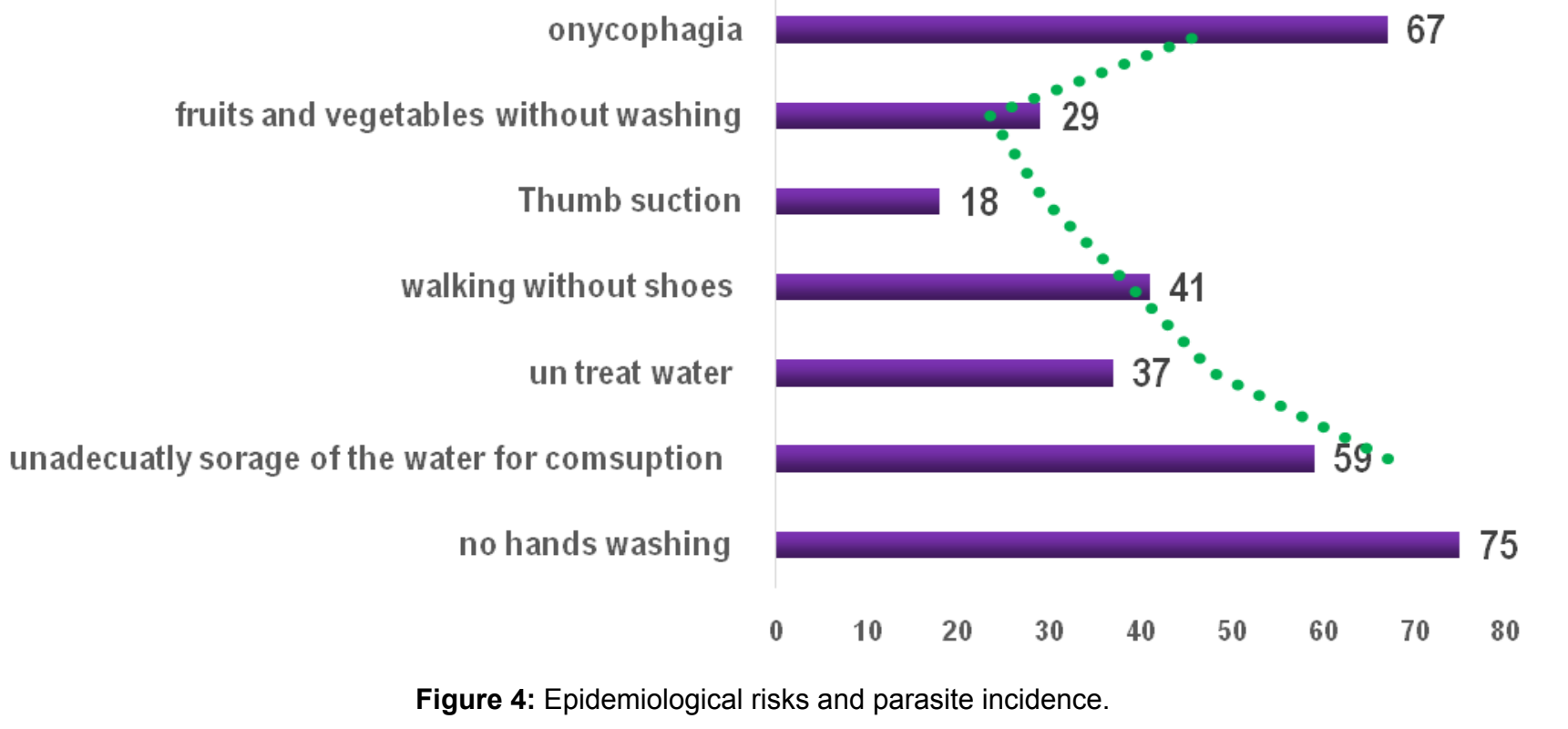

risk factors associated with intestinal parasitism, a close relationship was found with the age of the patients, and a higher incidence is shown in the earliest stages of life. The involvement by sex in the current study was similar to that described for population studies [7].

According to an investigation on factors associated with intestinal parasitism in the municipality of Matanzas, carried out by Domínguez, it can be seen that the prevalence is higher in 2-year-old children with $65.1 \%$, followed by 5 -year-old children, with $58.3 \%$. This does not correspond to the current study, however, if it coincides that the male sex is the most affected [8].

Other international studies correspond to the results of this investigation, such as Lacoste in Vegón de Nutrias belonging to Venezuela, Salcedo in six indigenous communities residing in Cali, Colombia; in which the condition in young patients stands out [9-12].

While other authors propose different clinical manifestations to those of the current investigation, Martínez determined that clinical cases with respect to Strongyloides stercoralis are typically manifested by dermatological, pulmonary or gastrointestinal disorders. In Cañete, in a study on liver fluke and fasciolosis, fever, abdominal pain, gastrointestinal disorders, hepatosplenomegaly, pain in the right hypochondrium, subxiphoid pain, ascites, icterus, urticaria, subcutaneous nodules and respiratory manifestations [13-19].

In a national survey carried out by Rojas, it is evident that the frequency of infections due to parasitic and commensal species in Cuba decreased over 25 years, it was observed that there was a decrease in the frequencies of infections for all species of soil-transmitted helminths, Trichuris trichiura, Ascaris lumbricoides, Ancylostomideos, and Strongyloides stercoralis. This same decrease in the frequency of infections in 2009 was found with the pathogenic protozoa Giardia lamblia and Entamoeba histolytica/E. disparate, and diners: Endolimax nana and Entamoeba coli. The only intestinal parasite that increased its frequency compared to the 1984 survey was Enterobius vermicularis (known as pinworm) [20].

In a Venezuelan study carried out by Lacoste, [14] given that there was a greater prevalence of infection by protozoa than by helminths, with Endolimax nana as the most prevalent, followed in order of frequency by Blastocystis and Entamoeba coli [14-20].

The study on intestinal parasitism by the author in Venezuela found that there was a predominance of higiénico ambientales inadequate habits, of which he stood barefoot walking, equal incidence shown in the previous unwashed food before eating [19-20].

It is concluded that there is a predominance of males, with a higher percentage of patients from rural areas. Digestive symptoms, such as abdominal pain and diarrhea, were the most reported by patients. The Giardia lamblia was the parasite most frequently identified in patients. Bad dietary hygiene habits are the main risk factors.

\section{Conflicts of Interest}

The author does not refer conflicts of interest.

\section{References}

1. Rojas CL, Angel Núñez CF, Aguiar PH, Silva Ayçaguer CL, Alvarez D, et al. (2012) Second national survey of intestinal parasitic infections in Cuba, 2009. Rev Cubana Med Trop 64: 15-21.

2. Nyantekyi L, Legesse M, Medhin G, Animut A, Tadesse K, et al. (2014) Community awareness of intestinal parasites 
and the prevalence of infection among community members of rural Abaye Deneba area, Ethiopia. Asian Pac J Trop Biomed 4: S152-S157.

3. Sinniah B, Sabaridah I, Soe MM, Sabitha P, Awang IP, et al. (2012) Determining the prevalence of intestinal parasites in three Orang Asli (Aborigines) communities in Perak, Malaysia. Trop Biomed 29: 200-206.

4. Díaz Murillo MP, Ramírez Sánchez NA, Osorio García SD (2013) The sense of intestinal parasitic diseases in American populations, identifying bioethical dilemmas. Rev Latinoam Bioét 13: 96-111.

5. Rodríguez Pérez M, González López ME, Cañete Villafranca R, Espinosa Triana D (2016) Results of an educational intervention on intestinal parasitism in medical personnel. Rev Cub Med Mil 45.

6. Wördemann M, Polman K, Menocal Heredia LT, Diaz RJ, Madurga AM, et al. (2006) Prevalence and risk factors of intestinal parasites in Cuban children. Trop Med Int Health 11: 1813-1820.

7. Escobedo AA, Cañete R, Núñez FA (2008) Prevalence, risk factors and clinical features associated with intestinal parasitic infections in children from San Juan y Martínez, Pinar del Río, Cuba. West Indian Med J 57: 377-382.

8. Domínguez León SI, Cañete Villafranca R, Martínez Morejón A, Gonzalez Enríquez M, Fuentes Gutiérrez Z (2011) Factors associated with intestinal parasitism in children's circles in the Matanzas municipality. Second semester, 2008. Rev Méd Electrón 33.

9. CañeteVillafranca R, Marcel Sounouve K, Prior García A, Noda Albelo A, Rodríguez Pérez M (2013) Helminthic infections of the digestive system: Current considerations ingles. Rev Méd Electrón 35.

10. Núñez Fernández FA, Hernández Pérez SM, Ayllón Valdés LL, Alonso Martín MT (2013) Epidemiological findings in intestinal parasitic infections of a group of children admitted for diarrhea. Rev Cubana Med Trop 65: 26-35.

11. Almirall $P$, Escobedo AA, Ayala I, Alfonso M, Salazar $Y$, et al. (2011) Mebendazole compared with secnidazole in the treatment of adult giardiasis: A randomized, no-inferiority, open clinical trial. J Parasitol Res 2011: 636857.
12. Almirall $P$, Bello J, Núñez FA, González OM, Fernández R, et al. (2013) Intestinal parasitosis in hospitalized children: Age distribution and clinical aspects. Rev Peru Epidemiol 17: 145 .

13. González Montero Y, Cañete Villafranca R, Machado Cazorla K, Álvarez Suárez A, Álvarez González B, et al. (2014) Intestinal parasitosis in patients admitted to the Antonio Guiteras Holmes Provincial Psychiatric Teaching Hospital. Matanzas, Cuba. Rev Méd Electrón 36: 139-148.

14. Lacoste Laugart E, Rosado García FM, Núñez FÁ, Rodríguez Peña MS, Medina Fundora IC, et al. (2012) Epidemiological aspects of intestinal parasitosis in children from Vegón de Nutrias, Venezuela. Rev Cubana Hig Epidemiol 50: $330-339$

15. Salcedo Cifuentes $M$, Florez $O$, Bermúdez A, Hernández L, Araujo C, et al. (2012) Intestinal parasitism prevalence among children from six indigenous communities residing in Cali, Colombia. Rev Salud Publica 14: 156-168.

16. Marin $\mathrm{H}$, Echezuria L, Sosa de Bermúdez E, Espinasa Maria C (2010) First Venezuelan consensus on parasitosis. Venezuelan Archives of Childcare and Pediatrics 73: 258.

17. Cardona Arias, Jaiberth Antonio, Bedoya Urrego, Katherine (2013) Frequency of intestinal parasites and evaluation of methods for their diagnosis in a marginal community of Medellín, Colombia. latreia 26: 257-268.

18. Cañete R, Rodríguez $P$, Sounouve KM, Brito K, Valdéz R, et al. (2014) Blastocystis sp. infection in patients with gastrointestinal complaints: A Cuban study. Turk Hij Den Biyol Derg 71: 165-170.

19. Gallego Jaramillo LM, Heredia Martínez HL, Salazar Hernández JJ, Hernández Muñoz TM, Naranjo García MM, et al. (2014) Identification of intestinal parasites in water from deep wells located in four municipalities of the state of Aragua, Venezuela, 2011-2012. Rev Cubana Med Trop 66: 164-173.

20. Cañete R, González ME, Almiral P, Figueroa I (2004) Infection with Giardia lamblia and Giardia lambliasis. Rev Panam Infect 6: 418. 